International Journal of Child, Youth and Family Studies (2014) 5(1): 204-219

\title{
“LIKE PICKING UP A SEED, BUT YOU HAVEN'T PLANTED IT": QUEER YOUTH ANALYZE THE IT GETS BETTER PROJECT
}

\author{
Shelley L. Craig, Lauren McInroy, Ramona Alaggia, and Lance T. McCready
}

\begin{abstract}
Youth who identify as lesbian, gay, bisexual, transgender, or queer [LGBTQ] are at elevated risk of experiencing verbal and physical harassment, as well as an array of negative outcomes, including increased violence and suicidality. The purpose of this study was to solicit input from LGBTQ youth $(n=19)$ about the strengths, limitations, and influence of an online video project focused on suicide prevention, the It Gets Better Project [IGBP]. Using a grounded theory approach, in-depth interviews were conducted and participant responses were analyzed using ATLAS.ti.6.7. Several major themes regarding participants' perspectives on the IGBP emerged from the analysis. Participants indicated that they perceived the IGBP as a positive start towards change, with the project drawing attention to the concerning issue of LGBTQ youth vulnerability for increased suicidality. However, they also identified flaws with the content and focus of the project, indicating the campaign requires significant further development to provide tangible resources to youth at risk of suicide. Recommendations are made and discussed to help inform future research and practice efforts.
\end{abstract}

Keywords: LGBTQ; youth; It Gets Better Project; media; suicide

Acknowledgements: The authors wish to acknowledge and thank the youth participants who generously provided their time and insight. This study was funded by a Social Sciences and Humanities Research Council of Canada Insight Grant (\#491406).

Shelley L. Craig, Ph.D., (the corresponding author) is an Assistant Professor in the FactorInwentash Faculty of Social Work, University of Toronto, 246 Bloor Street West, Toronto, Ontario, Canada, M5S 1A1. Telephone: (416) 978-8847. E-mail: shelley.craig@utoronto.ca

Lauren B. McInroy, MSW, RSW, is a doctoral student in the Factor-Inwentash Faculty of Social Work, University of Toronto, 246 Bloor Street West, Toronto, Ontario, Canada, M5S 1A1. E-mail: lauren.mcinroy@mail.utoronto.ca

Ramona Alaggia, Ph.D., is an Associate Professor and Chair in Children's Mental Health in the Factor-Inwentash Faculty of Social Work, University of Toronto, 246 Bloor Street West, Toronto, Ontario, Canada, M5S 1A1. E-mail: ramona.alaggia@utoronto.ca

Lance T. McCready, Ph.D. is an Associate Professor at the Ontario Institute for Studies in Education, University of Toronto, 252 Bloor Street West, Toronto, Ontario, Canada, M5S 1V6. E-mail: lance.mccready@utoronto.ca 
International Journal of Child, Youth and Family Studies (2014) 1: 204-219

Lesbian, gay, bisexual, transgender, and queer [LGBTQ] youth are frequently considered a population at risk (Morgan, Mancl, Kaffar, \& Ferreira, 2011). Though LGBTQ adolescents are not a homogenous population and do not experience all risks identically, these youth generally tend to have poorer emotional, psychological, behavioural, and educational outcomes than their non-LGBTQ peers (Fisher et al., 2008; Robinson \& Espelage, 2011). This population’s particularly high risk of suicidality in both the United States and Canada (Dyck, 2012) has led to research suggesting suicide is the "the leading cause of death among LGBTQ adolescents" (Fisher et al., 2008, p. 80), with some estimates indicating up to $40 \%$ of these youth have made a suicide attempt. Suicidality "refers to the occurrence of suicidal thoughts or suicidal behavior" (Galaif, Sussman, Newcomb, \& Locke, 2007, p. 27) and incorporates both cognitions and actions

Elevated LGTBQ youth suicidality has been linked to high rates of violence, discrimination, and identity-based bullying (Berlan, Corliss, Field, Goodman, \& Austin, 2010; Fisher et al., 2008; Morgan et al., 2011), as well as low levels of social support (Detrie \& Lease, 2007). For example, LGBTQ adolescents frequently experience verbal (80\%) or physical harassment (25 to $40 \%$ ) or violence (20\%) related to their sexuality and/or gender expression (Morgan et al., 2011). In Canada, a recent study found that one-fifth of LGBTQ students experienced physical violence as a result of their perceived LGBTQ status (Taylor \& Peter, 2011), contributing to poor health and mental health issues for this population

\section{The It Gets Better Project}

The It Gets Better Project [IGBP] (2012a) is an online video campaign created in 2010 by author and activist Dan Savage, and his partner Terry Miller, in response to the high-profile suicides of several male adolescents bullied for being, or perceived as being, gay in the United States that fall. The suicides of these LGBTQ young adults resulted in significant media attention that contributed to the creation and visibility of the IGBP (Gay Times, 2010; Gay-Straight Alliance Network, 2010; Make It Better Project, 2012b; Waidzunas, 2012). The project's stated goal is to let "all LGBT youth know, that despite the tough times, it gets better" (It Gets Better Project, 2012c), providing hope and a sense of community to youth experiencing harassment in order to prevent youth suicide (It Gets Better Project, 2012b; Parker-Pope, 2010). The IGBP emphasizes to youth that adulthood will be an improvement over their adolescence and provides examples of well-adjusted, successful LGBTQ adults as role models which youth may lack in their daily lives (It Gets Better Project, 2012b).

To achieve this goal, the IGBP is comprised of a growing compilation of videos uploaded by participants (both by LGBTQ individuals and non-LGBTQ allies) assuring youth of a brighter future by sharing their own stories (It Gets Better Project, 2012d; Parker-Pope, 2010; Waidzunas, 2012). Many celebrities, politicians, media personalities, and other notable individuals have also contributed to the project (It Gets Better Project, 2012b; Parker-Pope, 2011; Sparks, 2011). As of mid-2012 the project's website indicates that over 50,000 videos have been created by users, with a total of more than 50 million views (It Gets Better Project, 2012b). Additionally, over half a million people have taken the IGBP's pledge to support the IGBP, spread the campaign's message, and speak out against intolerance (It Gets Better Project, 2012a). Despite this extensive popularity, little is known about how LGBTQ youth view the strengths and limitations of the 
International Journal of Child, Youth and Family Studies (2014) 1: 204-219

IGBP, as well as their perspectives on the influence of this project on reduction of suicide risk. Scholarly attention to popular campaigns such as the IGBP is critical as there is little information on best practices or effective strategies to reduce suicide in LGBTQ youth (Dyck, 2012). The purpose of this study was to solicit input from LGBTQ youth concerning the messages imparted by the IGBP and their reaction to those messages.

\section{Methods}

\section{Study Design, Recruitment, and Data Collection}

This study sought the perspectives of LGBTQ young adults regarding the IGBP. A grounded theory design guided in-depth interviews with 19 LGBTQ young adults in the Greater Toronto Area of Ontario, Canada. Grounded theory was chosen as the methodology of this study due to its emphasis on a rigorous and systematic approach to data collection and theory building, as well as its encouragement of context exploration (Birks \& Mills, 2011; Patton, 2002). Participants were recruited through organizations and programs which specifically provided services or programming for LGBTQ youth. Youth were pre-screened to meet inclusion criteria: (a) age 18 to 22; (b) self-identified as members of the LGBTQ community; and (c) regular consumption of a variety of types of new media.

Eligible participants were recruited using theoretical sampling throughout the data collection period (between September and December of 2011). Theoretical sampling encouraged alternative and nuanced theoretical categories and assured a diversity of research participants, particularly with regard to sexual orientation and gender identity. Sampling and analysis were undertaken simultaneously so that emerging findings informed ongoing sampling (Charmaz, 2006; Strauss \& Corbin, 1998) until theoretical saturation was reached and little new information was coming forward in subsequent interviews (Charmaz, 2006; Creswell, 1998; McCracken, 1988). Interviews lasted between one and three hours, were conducted by the primary investigator (i.e., the corresponding author), and were simultaneously audio- and video-recorded. Participants provided informed consent in accordance with the approved University of Toronto Research Ethics Board Protocol \#26749. Interviews utilized a semi-structured interview protocol informed by current literature and developed by the research team. Open-ended questions gave participants the latitude to convey experiences relative to their individual perceptions and styles of presentation, while being prompted to remain within the scope of the interview topics.

Examples of questions included: Describe your reactions to the IGBP? and How do you think the IGBP influences queer youth? In addition, probes (e.g., Please describe what the IGBP does for youth? and What specifically would you suggest to improve the IGBP?) were also used to delve deeper into their initial statements. Participants were compensated with a gift card to a store of their choice, as well as bus tokens for transportation.

\section{Participants: Sample Description}

The mean age of participants $(n=19)$ was $19.47(S D=1.219)$, with an age range of 18 to 22. Participants identified their gender as cisgender-woman (47\%), cisgender-man (32\%), transgender-man (16\%), and genderqueer (5\%), resulting in 21\% of LGBTQ youth identifying 
International Journal of Child, Youth and Family Studies (2014) 1: 204-219

with a transgender identity. Cisgender (i.e., cisgender-woman or cisgender-man) refers to nontransgender individuals. Participants were lesbian (21\%), gay (32\%), bisexual (11\%), queer (5\%), polysexual (5\%), or using multiple terms (26\%). Participants also identified as White (74\%), Black (5\%), Asian (5\%), or multi-racial (i.e., Black/White, Black/Asian, and White/South Asian, 16\%). Ethnicity was more complex and thus more challenging to capture; however, 16\% of participants identified as ethnically Jewish, while 16\% identified as Hispanic.

Nearly all participants (95\%) were currently enrolled in school, with one participant currently in the process of applying. Of those attending school, 22\% were attending high school, while $11 \%$ were in college and $67 \%$ were in university. Participants were avid media users, particularly with regard to new, online media, with all participants spending more than five hours a week online. In the case of new media specifically, social networking, music and video sharing, and blogs/forums were particularly popular among participants. Participants were also asked about the amount of their television and online media consumption geared towards LGBTQ audiences or content, with study participants consuming a greater proportion of LGBTQ-focused content through new media.

\section{Analysis}

Grounded theory (Charmaz, 2006) strategies were used as an analytic framework. Grounded theory aims to create a systematic understanding of the relationship between experiences (Patton, 2002; Strauss \& Corbin, 1998). Essential elements of a grounded theory approach include ongoing and purposeful theoretical sampling, simultaneous data collection and analysis, multi-phase coding and analysis of data, continual reflection on the research and decision-making processes and comparison of preliminary analyses, theoretical saturation, and development of comprehensive theoretical explanations (Birks \& Mills, 2011; Charmaz, 2006). A grounded theory approach has been used in previous studies involving LGBTQ youth (Craig \& McInroy, 2014); Russell, Muraco, Subramaniam, \& Laub, 2009). All interviews were transcribed verbatim and uploaded into ATLAS.ti 6.7 software for data management and analysis. Transcripts of each session were independently analyzed by three coders, with seven coders participating in the project. After the generation of initial categories, open and axial coding led to the identification of concepts and eventually emergent themes (Strauss \& Corbin, 1998). Interrater reliability was reached at $98 \%$. Through consensus, codes were discussed and agreed upon leading to a shared understanding of the theme meanings, thus reducing bias (Denzin, 1994; Russell et al., 2009).

To ensure rigour and methodological soundness, trustworthiness measures were employed through credibility, confirmability, dependability, and transferability (Lincoln \& Guba, 1985). These included prolonged engagement (the research team has considerable experience working with LGBTQ youth and together represent expertise in quantitative and qualitative research methodologies), peer debriefing (numerous formal and informal meetings and discussions examined ideas and possible preconceived notions among the investigative team), and thick description (generated themes include rich descriptive accounts and quotes that present contexts and circumstances of sampled participants, findings, and interpretations). Dependability of the data was achieved through verbatim transcription of the audio-taped interviews so that the words of the participants were captured directly as they were spoken. In 
International Journal of Child, Youth and Family Studies (2014) 1: 204-219

addition, an audit trail comprised of an extensive collection of memos was maintained by the research team throughout the research study to describe the research process and track research decisions made along the way. Finally, awareness of potential presuppositions by the research team because of their previous experiences working with LGBTQ youth was examined through the use of reflexivity and bracketing, which consisted of debriefing after every interview and research team meeting and undertaking a frank analysis of the ways in which their own experiences may have influenced interpretation of the material.

\section{Results}

Four major themes regarding participants' perspectives on the IGBP and its influence on LGBTQ youth suicidality emerged from the analysis. Participants identified that the project was: (a) an excellent start, but (b) had a long way to go, and should focus on (c) making it better for all LGBTQ youth, (d) especially those that were more ethnically or socio-economically diverse. These results will be contextualized using relevant literature where appropriate, and described using the participants' own words.

\section{"I think it's an excellent start..."}

Participants universally agreed that the IGBP had some merit, or was at least an important start towards change. Many expressed the need for a campaign or programming reaching out to LGBTQ youth, and suggested that the IGBP was better than not having any campaign directed towards mitigating suicide risks for these adolescents.

The It Gets Better campaign is beautiful because, [it's] through social media, through a media that's accessible... It Gets Better, it's mostly people who are now in a better place than they were many years before, reaching out to people the same age as they were at a time of crisis saying look, please.... Please don't kill yourself because there are bullies.... So It Gets Better just says, you know what, it's a shitty world, but you can get through it.... So it's just a campaign for hope. (Phillip ${ }^{1}$, age 18, transgender-man/androgynous, gay)

Participants elucidated numerous strengths of the IGBP format, including the accessibility of the campaign, its contemporary relevance, the provision of role models, bringing attention to the issue of LGBTQ youth suicide, and its potential to decrease or prevent suicidality among LGBTQ adolescents. In particular, participants noted that the IGBP increased levels of awareness of the bullying and problems that LGBTQ youth have to contend with on a daily basis.

I guess we should continue with what we're doing, like getting the support out there and continuing the It Gets Better campaign and things like that, and bringing awareness to the fact that many LGBT guys and girls and people are dying because of bullying.... So I feel like we should bring awareness to the fact that people are dying because of hate. (Steven, age 19, cisgender-man, gay)

\footnotetext{
${ }^{1}$ Names have been changed to protect participant privacy
} 
International Journal of Child, Youth and Family Studies (2014) 1: 204-219

I think it fits with the times. Before people didn't want to talk about it because it's uncomfortable or most people just generally didn't care. But now you've got people out there saying you can't ignore this problem anymore and really active.... But I think it is definitely an excellent, it's a step in the right direction. (Michael, age 21, cisgender-man, gay/queer)

Participants praised the potential of the IGBP to reach out to LGBTQ youth and raise awareness of the issues LGBTQ youth face. Commentators have also discussed the importance of the IGBP (Waidzunas, 2012), such as the potential of its messages of support, as well as its encouragement of individuals to take actions (Sparks, 2011).

\section{“...But... it has a long way to go"}

Despite their recognition of the IGBPs strengths, participants noted that the project has some limitations, most notably that the campaign simply wasn't enough to raise awareness.

I think a lot of the messaging for It Gets Better is great for someone who's in those like initial stages.... Like I always think about It Gets Better as like picking up a seed... but you haven't planted it yet, you haven't watered it, it hasn't grown. (Suelia, age 22, cisgender-woman, queer)

Participants also echoed the significant critiques of the IGBP expressed in literature and popular media. While many commentators have acknowledged the notable contributions of the IGBP, they have also suggested that the project should be undertaken with greater care or thoughtfulness (Essig, 2010; Waidzunas, 2012). Participants largely felt that while the IGBP had potential, it also had substantial shortcomings, and needed to be developed further. In particular, several participants expressed the need for the IGBP to provide immediate and practical tools for adolescents to improve their current situation or mediate their suicidality. Additionally, participants identified systemic and social changes that need to occur.

I don't feel like it's at all where everyone feels that it is. I think it's like step one in a hundred step system. It's not step 50 in a 50 system, you know it's not like there. It's just this one piece and it was supposed to be like a kick-off for more stuff and that more stuff isn't happening and that's the problem. (John, age 19, transgenderman, queer/pansexual)

It is good that people are reaching out and saying "it can get better". But I don't feel like anyone should be saying it's going to get better automatically, just by virtue of more age. I think maybe it would be better if the campaign [said]... "it will get better if you do $X, Y$, and $Z$, or doing $X, Y$, and $Z$ will increase the chance that it will get better". And next Wednesday would be "Seek Out A Counsellor", [or] like "go to these websites and find some kind of community", or "read this article", or "go to this coffee house with other like-minded people". And these aren't like incredibly inventive suggestions, but, you know, just... like actual productive things 
International Journal of Child, Youth and Family Studies (2014) 1: 204-219

like a miserable 16 year old could do in the hopes that it would propel the getting betterness a little bit sooner than like just, you know, waiting and hoping till high school ends. (Laura, age 22, cisgender-woman, queer/pansexual)

Participants also noted that the campaign would do well to create opportunities to give youth a voice, which was also an objective of this research study. It was identified that not having resources or the ability to share your feelings and concerns could contribute to increased suicidality and that providing the space for youth to do so would be an important component of the future work of the IGBP.

[We need] to give that voice to youth because the reason so many youth are killing themselves is because they feel destitute, they feel like they don't have the resources, they feel like they don't have them accessible, they feel like they don't have a voice right. So the next step needs to be giving them a voice. (John, age 19 , transgender-man, queer/ pansexual)

Another issue raised by participants was the IGBP's focus on cisgender gay and lesbian adolescents, and its perceived lack of attention to other categories of LGBTQ youth. In particular, several mentioned the lack of representation of transgender people in the campaign. This is particularly problematic as transgender youth may be especially likely to experience LGBTQ-specific harassment, bullying, and violence compared to their cisgender LGBTQ peers. Nearly three-quarters (74\%) of transgender students in Canada experience verbal harassment and one-quarter (25\%) experience physical harassment (Taylor \& Peter, 2011). Some researchers remain critical of the media's disproportionate attention on the suicides of the young gay men in late 2010, and the suggestion that their deaths constitute a particular epidemic, rather than an example of the elevated suicide risk experienced by LGBTQ adolescents generally (Essig, 2010).

I think it's more geared to gay-lesbians sort of thing. It's kind of like trans[gender] people are like in another separate category. So in that way it's like they get left out, which isn't a good thing because I think that a lot of trans[gender] people they're skyrocketing too for suicides and nobody really takes stock of that. (Jimarcus, age 19, transgender-man, straight/questioning)

Although it has been suggested that this form of advocacy has the potential to pathologize LGBTQ youth as pitiable or tragic, rather than emphasizing the achievements or successes of the population (Essig, 2010; Waidzunas, 2012), these concerns were not highlighted by our participants. Yet these criticisms remain important to contextualize the youth perspective of the potential for improvement of IGBP.

\section{“Let's make it better"}

Numerous participants referenced a need to make changes for LGBTQ adolescents now rather than asking them to wait until they have survived high school.

It doesn't have to get better later, it doesn't have to get better in 10 years, it needs to happen now. There is no excuse, you know what I mean. You shouldn't have to 
International Journal of Child, Youth and Family Studies (2014) 1: 204-219

suffer those four years until it gets better because you're in Grade 9, and you know, it sucks to be in Grade 9 and be bullied when you have four years in front of you and you're like, oh my God, how am I going to get through this? (Anthony, age 19, cisgender-man, gay)

The next step to the It Gets Better Campaign has to be how do we make it better for them, you know, not let's just say it. (John, age 19, transgender-man, queer/pansexual)

Additionally, a number specifically referenced the Make It Better Project [MIBP] as being superior to, or going a step further than, the IGBP.

So it's changing it a bit, where, you know, not saying it'll get better no matter what; it's saying that you have to kind of change the context to make it better for you... Make It Better could be a stronger message. (Chris, age 21, cisgender-man, gay)

The MIBP, started and sponsored by the United States-based Gay-Straight Alliance Network, argues that youth should not have to experience bullying related to sexual orientation while in high school, and emphasizes making conditions better and schools safer for LGBTQ youth now rather than waiting for improvements to occur in the future (Make it Better Project, 2012a, 2012b). The MIBP, also created in response to the suicides in fall of 2010, views its campaign as going a step further than the IGBP by empowering youth to make changes in their current lives and addressing how people can make things better (Gay-Straight Alliance Network, 2010; Make It Better Project, 2012a, 2012b).

The MIBP seeks "to let students, parents, teachers, school administrators, and adult allies know that there are concrete actions they can take right now to make schools safer for all students” (Make It Better Project, 2012b), offering tangible strategies that individuals can use to contribute to the campaign, including letter writing and video blogging (Make It Better Project, 2012a).

Another recent local incarnation of this MIBP model mentioned by several participants is a youth-led organization entitled the "I Will Make It Better" Project [IWMIBP]. The project was developed by students at Etobicoke School of the Arts, a high school in the Greater Toronto Area. Officially begun in November 2011, IWMIBP's goal is "to raise awareness about the effects of bullying and to have people take a pledge against bullying” ("I Will Make It Better" Project, 2012a).

The IWMIBP seeks to work with schools, providing education on the topic of bullying and emphasizing the role of individual responsibility using real-life stories. The IWMIBP has provided presentations and anti-bullying workshops across Canada. The project has also received international media coverage, as well as support from local and international celebrities. This included a personal video of support from musician Lady Gaga at the project's official opening (“I Will Make It Better” Project, 2012a, 2012b). 
International Journal of Child, Youth and Family Studies (2014) 1: 204-219

“It gets better for a certain group of people..."

Participants also expressed the pitfalls of the IGBPs idealistic view of future outcomes and raised the issue of the IGBP setting unrealistic expectations for youth, and potentially causing them to take risks that could result in poor outcomes.

Like you can't just show too much positivity because what if, like this person's going to the parents and are like, oh, my parents are going to be perfectly fine because they love me, right. They go and they kick them out, so like their hopes are like gone, right. Like they have such high hopes, so happy coming out and excited, but then they get shoved right back down (Song, age 18, cisgender-woman, lesbian).

Participants critiqued the lack of attention to issues of socio-cultural diversity, individual context, and the social landscape within the project, as well as the fact that it simply may not get better for everyone.

I think... I think it's bullshit.... Mainly because I think the way that campaign was phrased and the way that it continues to be incorporated into things is that it gets better for a certain group of people. It gets better for gays and lesbians who are white and upper middle class and who have family support sometimes.... But for the most part at least the media.... That's how it's portrayed.... And if you don't, you have friends support, but it's always like.... It gets better for this group of people, that there's this like imaginary land.... In which we automatically end up going to after high school or after university and where everything is great, which in reality that's like so non-existent for so many people (Suelia, age 22, cisgender-woman, queer).

The relationship between environmental risks and suicidality for LGBTQ youth (Dyck, 2012) should be considered when developing suicide prevention strategies. As participants indicated, diversity in social location, context, experience, and opportunity should be taken into account in campaigns such as the IGBP.

\section{“Obviously it's gonna be better for you..."}

Many celebrities, politicians, organizations, sports teams, and other notable individuals have contributed to the IGBP, including: United States President Barack Obama; then United States Secretary of State Hilary Clinton; the staffs of Google, Disney, Pixar, The Gap, and Facebook; Major League Baseball teams the Boston Red Sox, the Baltimore Orioles and the San Francisco Giants; talk show hosts Ellen DeGeneres and Stephen Colbert; musicians Lady Gaga, Joel Madden, Ke\$ha, and Adam Lambert; and actors Anne Hathaway, Colin Farrell, and Neil Patrick Harris (It Gets Better Project, 2012b; Parker-Pope, 2011; Sparks, 2011; Waidzunas, 2012). The IGBP has been critiqued for being too heavily focused on the contributions of celebrities and politicians (Parker-Pope, 2011). 
International Journal of Child, Youth and Family Studies (2014) 1: 204-219

Participants commonly thought that the celebrity involvement was generally positive because of the IGBPs contribution of role models to youth development.

I'm extremely proud of all the people that have collaborated with that, especially all the movie stars, because youth and young people take movie stars as role models and when they see them post in a media, you tell them that it's okay to be gay, I feel like that makes them feel like there's hope for them. (Steven, age 19, cisgender-man, gay)

Others widely differed in their opinions about celebrity participation. While some liked their inclusion as relevant role models and examples of success in adulthood, others felt that celebrities gave LGBTQ adolescents unrealistic expectations of their future and were not particularly relevant to their lived experiences or the intent of the project. Here several respondents focused on the fact that while these celebrities were saying things get better, participants perceived that they were doing relatively little to actually improve the circumstances of LGBTQ youth experiencing violence.

I was like, okay, yeah, you can say that as a celebrity who has thousands of dollars now, who came out in like the tabloids once you were famous and like obviously it's gonna be better for you because you're already there.... And, I don't know it just.... It didn't speak to my reality, it didn't speak to a lot of my friends' realities, it didn't speak about any of the ways in which you can make it better. (Suelia, age 22, cisgender-woman, queer)

A number of participants also had issues with non-LGBTQ people, including celebrities, participating in a project specifically targeted to LGBTQ adolescents and seemingly speaking to an experience that was not their own. Notably, participants did not seem to be critiquing the involvement or support of non-LGBTQ allies in these types of campaigns, but were challenging the notion that non-LGBTQ people could make claims about the outcomes of experiencing LGBTQ-specific violence in adolescence.

I think it's good when queer people make these videos. But for a straight person to make a video, because I heard that there are a lot of straight people who are making these videos, I think that's a bit... because they haven't been through what it's like to be queer so they can't say, it gets better because how do you know, you're straight, you have this privilege. So I think that it was a little bit... I don't think straight people should have made those videos, but I think it was good that they had queer people making them. (Tiffany, age 19, cisgender-woman, bisexual)

\section{Discussion}

This study sought the views and perspectives of a sample of young people from the LGBTQ community about the IGBP, particularly the campaign's goal to address the issue of suicide risk for LGBTQ youth who are bullied and stigmatized. All participants had heard of the campaign although the depth of their knowledge varied widely. This universal recognition of the IGBP by participants may indicate the IGBP's success in getting the project's message to the 
target audience. Further, youth indicated that that they accessed the majority of LGBTQ-focused content through online sources, suggesting the potential of LGBTQ-focused new media campaigns (including the IGBP) to deliver messages of support. Participants indicated that they perceived the IGBP as a positive step towards changing the circumstances for LGBTQ youth experiencing identity-based violence and bullying, with the campaign drawing important attention to the issue of LGBTQ youth's elevated suicidality; thus attaining the project's goal to let "all LGBT youth know, that despite the tough times, it gets better" (It Gets Better Project, 2012c). Yet, youth identified that the project needed expansion beyond awareness raising to really make it better for all LGBTQ youth. It was also unclear whether the participants considered the campaign a form of suicide prevention. The link between the IGBP and suicide prevention appears to be fairly tenuous and should be further explored.

In addition, serious flaws in the format, content, and focus of the project were articulated and could be considered for further development of the campaign. Participants suggested that the IGBP was too passive as youth should not be expected to wait until adulthood for their situation to improve but deserve to have their lives changed immediately. Youth also identified that the involvement of celebrities and non-LGBTQ allies in the project allowed for a wider audience but encouraged less relevant content.

Youth also suggested that the campaign might not be as relevant to, or effective for, diverse LGBTQ adolescents because the campaign lacks attention to youths' individual contexts (e.g., race and ethnicity, socio-economic status, religion, etc.) and their socio-cultural landscapes (e.g., geographic location, social environment, etc.). Contemporary Canadian literature has likewise indicated that research on LGBTQ youth and suicidality has failed to attend to the potential impact of race/ethnicity, socio-economic status, and other socio-demographic and contextual factors (Dyck, 2012).

Participants challenged the researchers and the broader LGBTQ community to build on the awareness generated from the IGBP and to provide more concrete strategies to impact youth suicide. For example, the movement to change the current school environment by the MIBP and the IWMIBP is an element not addressed by the IGBP. This attention to school climate is essential, as a recent Canadian study found that 64\% of LGBTQ students state that school is unsafe for them (Taylor \& Peter, 2011). The risks of this hostile educational climate frequently include poor academic outcomes, truancy, and attrition, which impacts future opportunities (Crisp \& McCave, 2007; Robinson \& Espelage, 2011; Craig \& Smith, 2014).

In contrast, positive school environments, with supportive personnel, LGBTQ-specific programs, and anti-discrimination policies, may provide protection against victimization and contribute positively to academic outcomes and self-esteem (Crisp \& McCave, 2007; Griffin, Lee, Waugh, \& Beyer, 2004; Craig, 2013). The IGBP's focus on asking youth to wait out their high school years may be an important message of hope but, as the participants indicated, youth need tangible help now. Organizations are taking steps, as a recent report by the Egale Canada Human Rights Trust has called for immediate action on LGBTQ youth suicidality by creating an integrated suicide prevention strategy (Dyck, 2012). 
International Journal of Child, Youth and Family Studies (2014) 1: 204-219

\section{Limitations}

As with all research, this study is subject to certain limitations. The sampling strategy was driven by the need for in-depth investigation and thus the sample was limited in size and not intended to be representative of all LGBTQ youth or those that use new media infrequently. Findings are primarily transferable to other well-educated LGBTQ youth from relatively resourced backgrounds in urban contexts. Further, participants were all fluent in conversational English, and the majority spoke English as their first language. Since participants were required to contact our study team for an eligibility screening, selection bias may have resulted in a sample that was different than those not making contact. The study location, Toronto, is also significant as there is a well-established, active LGBTQ community, and a variety of organizations and services specifically serving LGBTQ youth. Finally the IGBP, while international in the scope of its efforts (It Gets Better Project, 2012b), is designed and operated in the United Sates, and it should be acknowledged that our Canadian sample may differ in a substantive way from the American youth the campaign is primarily designed to reach.

\section{Recent Developments and Future Directions}

More than two years after its start, the campaign remains popular. Six months after the IGBP began, a book on the project edited by Dan Savage and Terry Miller was released entitled It Gets Better: Coming Out, Overcoming Bullying, and Creating a Life Worth Living (2011), and in February 2012 youth-oriented television network MTV released a one-hour documentary on the project (It Gets Better Project, 2012a). As of mid-2012 the project continues to receive significant traffic on its website and media attention, with MTV releasing a second special in early October 2012 (It Gets Better Project, 2013). Further, similar campaigns continue to develop such as the IWMIBP launched in the Greater Toronto Area in late 2011. However, despite the overwhelming visibility and popularity of these projects, to our knowledge no rigorous research exists on the influence of these campaigns on the reduction of bullying and the reduction of suicidality of LGBTQ adolescents. Future research should endeavour to measure the effects of these new media campaigns on both youth suicidality and overall community awareness, as well as identify the role that the media plays in the identity development of LGBTQ youth.

\section{Conclusion}

This qualitative study explored the opinions of LGBTQ youth about the influence of the It Gets Better Project [IGBP] on bullying and suicide prevention. Participants underscored that new media (e.g., social networking, YouTube, etc.) has great potential for reaching LGBTQ youth. Youth offered that the IGBP is a good starting point to raise awareness, but should evolve into tangible strategies to make it better for youth already experiencing risk. In addition, the link between the project and suicide prevention is not clear or strong and may not be particularly helpful for youth already experiencing significant distress. Findings highlight the need to include youth in campaign and program development. As the IGBP strives to intended to address the bullying and suicide risk of LGBTQ youth through new media, it will be critical to take action to further these efforts and provide immediate interventions to reduce the suicidality of LGBTQ youth. 
International Journal of Child, Youth and Family Studies (2014) 1: 204-219

\section{References}

Berlan, E. D., Corliss, H. L., Field, A. E., Goodman, E., \& Austin, S. B. (2010). Sexual orientation and bullying among adolescents in the growing up today study. Journal of Adolescent Health, 46(4), 366-371. http://dx.doi.org/10.1016/j.jadohealth.2009.10.015

Birks, M., \& Mills, J. (2011). Grounded theory: A practical guide. Thousand Oaks, CA: Sage Publications Inc.

Charmaz, K. (2006). Constructing grounded theory: A practical guide through qualitative analysis. Thousand Oaks, CA: Sage Publications.

Craig, S. L. (2013). Affirmative supportive safe and empowering talk [ASSET]: Leveraging the strengths and resiliencies of sexual minority youth in school-based groups. Journal of LGBT Issues in Counseling, 7, 1-15.

Craig, S. L., \& McInroy, L. (2014). You can form a part of yourself online: The influence of new media on identity development and coming out for LGBTQ youth. Journal of Gay and Lesbian Mental Health, 18(1), 95-109. DOI: 10.1080/19359705.2013.777007.

Craig, S. L., \& Smith, M. (2014). The impact of perceived discrimination and social support on the school performance of multiethnic sexual minority youth. Youth \& Society, 46, 3050. DOI: $10.1177 / 0044118 X 11424915$

Crisp, C., \& McCave, E. L. (2007). Gay affirmative practice: A model for social work practice with gay, lesbian, and bisexual youth. Child and Adolescent Social Work Journal, 24(4), 403-421. http://dx.doi.org/10.1007/s10560-007-0091-z

Creswell, J. W. (1998). Qualitative inquiry and research design: Choosing among five traditions. Thousand Oaks, CA: Sage Publications, Inc.

Denzin, N. K. (1994). The art and politics of interpretation. In N. K. Denzin \& Y. S. Lincoln (Eds.), Handbook of qualitative research (pp. 500-516). Thousand Oaks, CA: Sage.

Detrie, P. M., \& Lease, S. H. (2007). The relation of social support, connectedness, and collective self-esteem to the psychological well-being of lesbian, gay, and bisexual youth. Journal of Homosexuality, 53(4), 173-199. http://dx.doi.org/10.1080/00918360802103449

Dyck, D. S. (2012). Guide for the development of an LGBTQ youth suicide prevention strategy. Egale Canada Human Rights Trust. Retrieved March 7, 2013, from http://egale.ca/wpcontent/uploads/2012/12/LGBTQ-YSPS-Conference-Paper.pdf 
International Journal of Child, Youth and Family Studies (2014) 1: 204-219

Essig, L. (2010, October 3). Queer youth not a tragedy (Web log post). The Chronicle of Higher Education. Retrieved August 24, 2012, from http://chronicle.com/blogs/brainstorm/queer-youth-not-a-tragedy/27380

Fisher, E. S., Komosa-Hawkins, K., Saldaña, E., Thomas, G. M., Hsiao, C., Rauld, M., \& Miller, D. (2008). Promoting school success for lesbian, gay, bisexual, transgendered, and questioning students: Primary, secondary, and tertiary prevention and intervention strategies. The California School Psychologist, 13, 79-91. http://dx.doi.org/10.1007/bf03340944

Galaif, E. R., Sussman, S., Newcomb, M. D., \& Locke, T. F. (2007). Suicidality, depression, and alcohol use among adolescents: A review of empirical findings. International Journal of Adolescent Medicine and Health, 19(1), 27-36. http://dx.doi.org/10.1515/ijamh.2007.19.1.27

Gay-Straight Alliance Network. (2010). In response to LGBT youth suicides, Gay-Straight Alliance Network launches Make It Better Project: Giving youth tools to combat antiLGBT bullying and prevent suicide. Retrieved August 24, 2012, from http://gsanetwork.org/news/youth-suicides-prompt-make-it-better-project/100310

Gay Times. (2010, November 2). In this issue: GT investigates. Retrieved August 24, 2012, from http://www.gaytimes.co.uk/Magazine/InThisIssue-articleid-7574-sectionid-742.html

Griffin, P., Lee, C., Waugh, J., \& Beyer, C. (2004). Describing roles that gay-straight alliances play in schools: From individual support to school change. Journal of Gay \& Lesbian Issues in Education, 1(3), 7-22. http://dx.doi.org/10.1300/j367v01n03_03

It Gets Better Project. (2012a). It Gets Better project. Retrieved August 24, 2012, from http://www.itgetsbetter.org/

It Gets Better Project. (2012b). About the It Gets Better project. Retrieved August 24, 2012, from http://www.itgetsbetter.org/pages/about-it-gets-better-project/

It Gets Better Project. (2012c). It Gets Better project: Contribute. Retrieved August 24, 2012, from https://secure.itgetsbetter.org/page/contribute

It Gets Better Project. (2012d). It Gets Better project: Submit a video. Retrieved August 24, 2012, from http://www.itgetsbetter.org/page/s/submit-a-video

It Gets Better Project. (2013). Second It Gets Better special full episode (Video). Retrieved March 13, 2013, from http://www.itgetsbetter.org/pages/second-it-gets-better-special-toair-on-mtv-october-9th

“I Will Make It Better” Project. (2012a). The “I Will Make It Better” project: About. Retrieved from http://www.mygsa.ca/node/10117

“I Will Make It Better” Project. (2012b). The “I Will Make It Better” project: Mission statement. Retrieved August 24, 2012, from http://iwillmakeitbetter.org/ 
International Journal of Child, Youth and Family Studies (2014) 1: 204-219

Lincoln, Y. S., \& Guba, E. G. (1985). Naturalistic inquiry. Newbury Park, CA: Sage Publications, Inc.

Make It Better Project. (2012a). About. Retrieved From http://www.facebook.com/makeitbetterproject\#!/makeitbetterproject/info

Make It Better Project. (2012b). What is the Make It Better project? Retrieved August 24, 2012, from http://www.makeitbetterproject.org/about

McCracken, G. (1988). The long interview. Qualitative research methods (Vol. 13). Newbury Park, CA: Sage.

Morgan, J. J., Mancl, D. B., Kaffar, B. J., \& Ferreira, D. (2011). Creating safe environments for students with disabilities who identify as lesbian, gay, bisexual, or transgender. Intervention in School and Clinic, 47, 3-13. http://dx.doi.org/10.1177/1053451211406546

Parker-Pope, T. (2010, September 22). Showing gay teenagers a happy future. The New York Times. Retrieved August 24, 2012, from http://well.blogs.nytimes.com/2010/09/22/showing-gay-teens-a-happy-future/

Parker-Pope, T. (2011, July 5). Talking about the It Gets Better Project. The New York Times. Retrieved August 24, 2012, from http://well.blogs.nytimes.com/2011/07/05/talkingabout-the-it-gets-betterproject/?scp=2\&sq=it\%20gets\%20better\%20project\%20dan\%20savage\&st=cse

Patton, M. (2002). Qualitative research and evaluation methods (3rd ed.). Thousand Oaks, CA: Sage.

Robinson, J. P., \& Espelage, D. L (2011). Inequities in educational and psychological outcomes between LGBTQ and straight students in middle and high school. Educational Researcher, 40(7), 315-330. http://dx.doi.org/10.3102/0013189x11422112

Russell, S., Muraco, A., Subramaniam, A., \& Laub, C. (2009). Youth empowerment and high school gay-straight alliances. Journal of Youth and Adolescence, 38(7), 891-903. http://dx.doi.org/10.1007/s10964-008-9382-8

Savage, D., \& Miller, T. (Eds.). (2011). It gets better: Coming out, overcoming bullying, and creating a life worth living. Boston: Dutton.

Sparks, A. (2011). Celebrities Supporting LGBT project “It Gets Better”. Psych Central. Retrieved August 24, 2012, from http://blogs.psychcentral.com/celebrity/2010/10/celebrities-supporting-lgbt-project-itgets-better/

Strauss, A., \& Corbin, J. (1998). Basics of qualitative research: Grounded theory procedures for developing grounded theory (2nd ed.). Thousand Oaks, CA: Sage Publications. 
International Journal of Child, Youth and Family Studies (2014) 1: 204-219

Taylor, C. \& Peter, T. (2011). Every class in every school: The first national climate survey on homophobia, biphobia, and transphobia in Canadian schools. Egale Canada Human Rights Trust. Retrieved March 7, 2013, from http://egale.ca/wpcontent/uploads/2011/05/EgaleFinalReport-web.pdf

Waidzunas, T. (2012). Young, gay, and suicidal: Dynamic nominalism and the process of defining a social problem with statistics. Science, Technology, \& Human Values, 37(2) 199-225. http://dx.doi.org/10.1177/0162243911402363 